\title{
Cyberbullying and Traditional Bullying: Parents' Perceptions of Their Child with Learning Disabilities
}

\author{
Tali Heiman and Dorit Olenik Shemesh
}

\section{Department of Education and Psychology The Open University of Israel108 Ravutski Street. Raanana, Israel}

\begin{abstract}
The present study examined 85 parents' perceptions of their child with learning disabilities (LD) Internet usage, cyberbullying and traditional bullying involvement, as related their child's social support, loneliness and depressive mood. Results revealed that most parents reported that their child was rarely involved in cyberbullying, as victim or as bully, and more involved in traditional bullying. Most parents suggested reporting the authorities when getting involved with cyberbullying, while half of them suggested consulting an adults concerning traditional bullying. Positive correlations were obtained between the child being a victim of traditional bullying, lower social support, feeling loneliness, and depressive mood, and between cybervictimization and depressive mood, whereas a cyber-perpetrator was negatively correlated with family support and depressive mood.
\end{abstract}

\section{INTRODUCTION}

Few Studies Have Explored The Parents' Perceptions Of Their Child Experience Of Traditional And Cyberbullying (Vollink, Dehue, Mc Guckin, \& Jacobs, 2016). Focusing On The Relationships Parents-Child, Mesch (2009) Found That Parental Mediation Serve As A Protective Factor For Cybervictimization. As Such, Within Families Where Parental Rules Were Stricter Regarding The Internet Usage Of Their Children, The Youth Risks Of Being Cyber Victimized Decreased. Livingstone And Helsper (2008) Found That Parental Restrictions On Child's Online Activity, Predicted A Lower Level Of Overall Teenagers' Online Risks, But Parental Restriction Not Always Were Effective In Reducing Risk. A Survey Conducted Among 802 Parents And Their Adolescent Children (Madden, Cortesi, Gasser, Lenhart, \& Duggan, 2012) Showed That 72\% Of Parents Were Concerned About Their Child Online Interactions With People They Do Not Know, And 69\% Of Parents Expressed Their Concerned About The Effects Of Their Child's Online Activity On The Child Reputation And Academic Achievements. Other Study (Stadler, Feifel, Rohrmann, Vermeiren, \& Poustka, 2010) Found That High Levels Of Parental Support Could Protect Against Maladjustment, And PeerVictimization In Adolescents. Parent Involvement And Supervision Of Their Child's Internet Usage May Represent A Central Role In Cyberbullying Prevention. Most Parents Reported That They Had Set Rules Regarding With The Use Of The Internet For Their Child; However, These Same Parents Were Not Aware Of The Harassment And Cyber Victimization Of Their Child As Well As Underestimated Their Own Child's Bullying Behavior (Dehue, Bolman, \& Vollink, 20088). Furthermore, It Appears That Adolescents' Disclosure To Their Parents About Their Online Activities, Reduced The Online Aggressive Messages Sent By The Adolescents (Law, Shapka, \& Olson, 2010). Limited Studies Have Examined Parents' Perceptions Regarding Their Own Child's Involvement In Cyberbullying, Especially With Children And Adolescents With Learning

Disabilities

Learning disabilities (LD) was defined by the Diagnostic and Statistical Manual of Mental Disorders (DSM-5, 2013), as the individual's academic skills are below the average range of scores in appropriate tests and the individual shows persistent difficulties in reading, writing, or mathematical reasoning skills. These individuals might exhibit inaccurate or slow reading, poor written expression, difficulties remembering number facts, or inaccurate mathematical reasoning. Various studies indicated that students with LD are at higher risk of being victims of bullying (traditional and cyberbullying) and experiencing social and emotional difficulties (Mishna, 2003). Findings of Kokkinos and Antoniadou study (2013) on 346 students, shows that students with LD were significantly more bullies or victims, were more socially excluded and had more difficulties in forming positive mutual social relationships compared to peers without disabilities. A recent study on traditional bullying (Hartley, Bauman1, Nixon, \& Davis, 2015) among 3,305 students in general and special education classes, found revealed that students attending special education classes were more vulnerable (physically and emotionally) and more targeted to victimization with higher levels of psychological distress compare to students in general education. Similarly, it was found an increased perpetration rates among students with LDs compare 
to students without LD (Rose, Monda-Amaya, \& Espelage, 2011). Examining the incidence of traditional bullying among adolescent students with LD in Israel, revealed that $25 \%$ of high school students reported being involved in verbal violence, and 14\% reported being involved in physical aggression. Moreover, the prevalence of cybervictimization of adolescent students with LD was 27\% (Heiman \& Olenik Shemesh, 2013). Although cyberbullying involvement concerned parents, many adolescents do not tend to share their experiences regarding their involvement in cyberbullying, or hardly discuss their personal problems or their social difficulties with their parents and or their teachers. Singer (2005) indicated that students with dyslexia, rarely reported to their teacher the occurrence of bullying or teasing, and only $28 \%$ of them consider their teachers to be a source of support. Furthermore, it was found that children and adolescents with disabilities are more likely to be victims, they delayed disclosure and have more difficulty reporting their experiences (Hershkowitz, Lamb, \& Horowitz, 2007). Thus, adolescents with LD are at a higher risk for cyberbullying involvement due to their social and emotional difficulties.

\section{Bullying and cyberbullying as related to social and emotional aspects}

Most studies have defined cyberbullying as an aggressive behavior conducted by a person or a group of people through the internet (Smith, Mahdavi, Carvalho, Fisher, Russell, \& Tippett, 2008) which involves the intention to harm through a variety of electronic media, verbal and/or visual messages (Hinduja \& Patchin, 2013). Traditional bullying was defined as an intentional aggressive behavior that includes three main aspects: physically, as hitting, kicking; social relations as social exclusion, spreading rumors; verbal bullying, as teasing, calling name (Olweus, 1993). The phenomenon of cyberbullying and traditional bullying have psychological effects, as victims can have depressive symptoms, low self perception, low academic achievement (Hinduja \& Patchin, 2010; Mason, 2008). The relationships between bullying (traditional or by the internet) was supported by the results of the research study (Ramsey, DiLalla, \& McCrary, 2015) that found that participants who reported low levels of both traditional bullying and cyberbullying also reported on lowest depressive symptoms. Following studies that explore the relationships between students with LD, social support and emotional aspects as sense of loneliness and depression, findings revealed that these students might exhibit a wide range of maladaptive behaviors, lack of appropriate social skills, higher levels of stress and anxiety, lower academic selfefficacy (Hen \& Goroshit, 2014), as well as reporting higher sense of loneliness, low self-esteem, and depression as compared to their peers without LD (Margalit \& Al-Yagon, 2002). Mammarella and her colleagues (2014) indicated that children with reading disabilities and with nonverbal LD reported higher levels of social anxiety and depressive symptoms. Studies on social and emotional difficulties of students with LD showed that $24-52 \%$ of them report significant social and emotional distress (Dyson, 2003). Examining the relationship between cyberbullying, traditional bullying and loneliness of adolescents (Brighi, Melotti, Guarini, Genta, Ortega, Mora-Merchan, Smith, \& Thompson, 2012) revealed that students who have been cybervictims report greater feelings of loneliness within the family, whereas victims of traditional bullying report a higher level of social loneliness. Furthermore, social support was negatively associated with cyberbullying involvement (Olenik-Shemesh, Heiman, \& Eden, 2012), and positively association was found between cyber victimization, depressive symptoms and suicidal thoughts (Hinduja \& Patchin, 2010). Other researchers suggest that feelings of loneliness and depression could lead both the attackers and victims to involvement in violence and crime, through to extreme events in which cyberbullying have led to suicide (Hinduja \& Patchin, 2010).

The present study focuses on the following aspects: (1) examining the parent's perception of their child with LD patterns of Internet usage and their involvement as a victim or a perpetrator in traditional bullying and in cyberbullying. (2) examining the parent's perception of ways for coping with bullying and cyberbullying, and (3) examining the perceived relations between social support, sense of loneliness, and depressive mood with being involved in cyberbullying or in traditional bullying situations.

\section{METHOD}

Participants

Participants included 85 parents of a child diagnosed with LD (64 mothers, 21 fathers). Parents' age range was 30-57 years $(M=44.7, S D=5.75)$, education range was $12-24$ years, $(M=15.8, S D=3.17)$ with a medium to high economic status loving in the central part of Israel. Parents completed their marital status $(n=61$ were married, 71.76\%; $\mathrm{n}=24$ were a single parent, 28.24\%) and their occupation varied from secretary, accountability, teachers, marketing and working in sales, lawyer and high tech industries. Children's ages ranged between 10 and $16(M=12.91, S D=2.71)$ with 53 boys and 32 girls. Individuals who have been diagnosed as having LD met the criteria that included detailed informal measures of cognitive abilities and achievement abilities, showing specific difficulties in academic skills such as reading, writing, spelling, arithmetic or mathematics (Israeli Ministry of Education, 2014; National Joint Committee on Learning Disabilities-NJCLD, 1994). Parents completed their child diagnosis, which referred to 45 children with LD with reading and writing difficulties, 8 with dyscalculia and mathematics difficulties, 25 with comorbid LD and 
hyperactivity or attention deficit disorder, 6 with comorbid LD and other emotional or mental illness disabilities, one child with LD and Asperger symptoms.

\section{PROCEDURE}

The study received approval from the University Ethics Committee permission for the distribution of the questionnaires among the parents. During three different meetings of the Israeli National Organization for people with LD, parents were asked to volunteer to complete anonymously the questionnaires on the bullying and cyberbullying involvement of their child. Out of $\mathrm{f} 106$ parents, 85 of them (80.19\%) completed the questionnaires.

\section{MEASURES}

Parents completed four questionnaires in order to examine the parent's viewpoint of their child.

Cyberbullying and Traditional Bullying (Smith, et al., 2008). This questionnaire consists of 22 items relating to the following issues: patterns and characteristics of internet use, cyberbullying and traditional bullying, perception of the severity of cyberbullying compared to traditional bullying, ways of coping and reactions to cyberbullying and traditional bullying. The items included parent's estimation of their child's involvement in cyberbullying: Has your child been cyber bullied by pictures, messages, emails, social networks? Parents received a list of ways to deal with cyberbullying and traditional bullying (alpha $=0.89$ ).

Multidimensional Scale for Social Support (Zimet, Dahlem, Zimet, \& Parkley, 1988). The questionnaire includes 12 items to assess the parent's perceived support for the child by family, friends and/or a significant other. The scale ranging from very unsuitable (1) to very suitable (7). Three categories were obtained: Family support (My family is willing to help me to make decisions), friends support (He/she can talk about his/her problems with friends) and for the support of a significant other (He/she has someone close that he/she can share with grief and joyful feelings). Scores range from 4 to 28, with greater scores indicating more support. Reliability for family support, friends' support and for the support of a significant other was high (alpha $=0.95$; $0.92 ; 0.95$, respectively).

Loneliness Questionnaire (Asher, Hymel, \& Renshaw, 1984). The questionnaire includes 16 items which are rated on a five-point scale ranging from he/she never feels this way (1) to he/she always feels this way (5). For example: he/she feels alone; it's hard for him/her to make friends. Scores range from 16 to 80, with greater scores indicating more feeling of loneliness (alpha $=0.90)$.

Children's Depression Inventory Questionnaire (Kovacs \& Beck, 1977). The questionnaire includes 14 items rated on a three-point scale ranging from never feel this way (0) to always feel this way (2). For example: nobody really loves him/her; nothing will ever work out for him/her. Scores range from 0 to $54($ alpha $=0.82)$.

\section{Analytic Plan}

Data were analyzed using SPSS, version 22 for Windows. First, descriptive statistics were calculated to examine the parent's perceived Internet surfing patterns of their child and perceived their child as cybervictim vs. traditional victim; cyber perpetrators vs. traditional perpetrator.

Then we examined parents' advice for coping with cyberbullying and traditional bullying, and the relationships between Parents' reports on cyberbullying, traditional bullying as related to social and emotional variables.

\section{RESULTS}

Parents' perceptions of their child Internet usage

Descriptive statistics were calculated to examine the parent's perceived surfing patterns of their child. Results indicated that almost half of the parents $(n=41,48.2 \%)$ reported on excellent computer ability of their child, some parents $(n=21,24.7 \%)$ reported on good computer expertise, others $(n=22,25.9 \%)$ perceived their child with medium-low expertise and only one parent estimated low computer ability of the child (range: low $=1$ to excellent $=4 ; \mathrm{M}=3.2, \mathrm{SD}=0.87)$. Parents reported that their child usually surf at home $(71.8 \%)$, mostly for playing computer games $(67.1 \%)$, for school projects $(56.5 \%)$, sending emails $(43.5 \%)$ or downloading music $(36.5 \%)$. Table 1 shows that most parents reported that their child had never experienced any form of bullying. Traditional victimization and traditional perpetrator were more frequent than cybervictimization or cyberperpetrator. Only few parents reported that their child was cybervictimized during the last 6 months compared to the previous year's occurrences $(2.35 \%$ vs. $5.8 \%)$, while reports on traditional victimization occurrences were much more frequent ( $14.1 \%$ during the last 6 month vs. $46 \%$ during the previous year). As for perceived child perpetrator, some parents admitted that their child initiated verbal, social or physical bullying but very few reported on their child as a cyberperpetrator. The results show in Table 2 described parents perception of their child best ways to cope with cyberbullying and traditional bullying. Regarding cyberbullying, parents could report on more than one answer, thus the total score is more than 100\%: Parents suggested reporting to the police or the authorities about the cyberbullying, blocking the insulting messages or 
documenting the insulting messages. Almost half of the parents suggested that the child will tell an adult, and advised them to change their email address or phone number. Fewer recommended ignoring the messages, or asking the cyber perpetrators to stop, and very few suggested revenge and attacking back through the net.

Concerning the child coping with traditional bullying, parents reported that their child might consult or tell to a parent, teacher, school counselor or the school principal, while some parents did not know how their child will deal with traditional bullying.

Relationships between cyberbullying, traditional bullying and social-emotional measures

As Table 3 shows, the correlations between social support, loneliness, depressed mood and traditional victimization or perpetrators were generally significant and medium-high compared to cybervictimization or cyberperpetrators. Significant negative relationships were found between traditional victimization, general social support and friends' support, and positive correlations were found with loneliness measures and a depressive mood. Results considering traditional perpetration revealed significant and negative correlations with general social support, family and friend support, while a positive correlations was found with a depressive mood. Concerning cyber situations, cybervictimization and cyberperpetrators were significantly correlated with a depressive mood. Cyber perpetrators were significantly negatively correlated with family support. In addition, significant correlations were obtained between victims and perpetrators in traditional bullying situations $(\mathrm{r}=$ $.47)$, and between perpetrators in both bullying situations: traditional and cyber $(\mathrm{r}=.48)$.

\section{DISCUSSION}

The goal of the present study was to examine parents' perception regarding their child with LD patterns of Internet usage, and the child's involvement in cyberbullying and traditional bullying. The findings of the current study revealed that most parents $(72.9 \%)$ reported that their child never initiated traditional bullying and similar patterns exist for cyberbullying perpetrators as almost all the parents $(90.6 \%)$ reported that their child never cyberbullied others. Few parents reported that their child was a perpetrator of cyberbullying through email or messages, and more parents reported on traditional victimization compared to cybervictimization. Within the present study, parents reported on a lower estimation of their child involvement in bullying compared to USA Statistics Data (2014) on bullying reports of students' involvement in cyberbullying (52\%) and in school traditional bullying (77\%). Following previous studies (Heiman \& Olenik Shemesh, 2013; Rigby, 2013) reporting that students with LD were generally highly involved in cyberbullying, considering the present data, it appears that the parents were less/or not awarded regarding their child involvement in traditional bullying or cyberbullying. This lack of parent awareness of cyberbullying can be a consequence of poor parent awareness to the child Internet usage, or it can be attributed to the fact that most parents are not familiar with the expression and characteristics of online bullying and its risky aspects. This unawareness of bullying involvements is significantly higher with regard to cyberbullying. Previous studies (Li, 2006; Smith et al., 2008) found that the majority of the cyberbullying victims did not report the incidents to a parent or an adult and tried to cope with the phenomenon alone. Yet, victims of traditional bullying had as higher tendency to tell and to seek for help compared to victims of cyberbullying. Thus, the percentage of parents who reported that their child was engaged in cyberbullying (as a bully or victims) was found to be considerably low.

The second research objective addressed parent perception concerning the ways for coping with bullying. It appears that parents are perceived by their children as less familiar with the virtual social media and less aware of cyberbullying, thus students often express fear that parents will not understand their situation and may even forbid or restrict their Internet usage (Campbell, Spears, Slee, Butler, \& Kift, 2012; Ševčíková, Šmahel \& Otavová, 2012). Specific programs for parents might be useful in order to enhance their knowledge and coping with risky behavior in the Internet. The third research objective addressed the relationships between parents' perceptions of the child's social support, feelings of loneliness, depressive mood, and being involved in cyberbullying or in traditional bullying. The data indicated significant correlations between the measures. The findings of the present study revealed that parents report on significant relationships between traditional bullying (as victims and perpetrators) and cybervictim and cyberperpetrator involvement with social-emotional measures. Moreover, parents reported on a high correlation between traditional victimization and perpetrator situations $(\mathrm{r}=.47)$. It appears that parents are more familiar with traditional bullying events compared to the cyberbullying. Additional studies are needed to examine parents' view regarding the impact of the social networks on their child's social-emotional behavior compare to the child perspective. In addition, the data revealed no significant correlation concerning parent perception between being a victim of traditional bullying and being a cybervictim. Some findings indicated a positive correlation between being a traditional victim and being a cybervictim (Dehue et al., 2008), while other findings suggested that a person who is a traditional victim may not necessarily be a cyber victim as well (Smith et al., 2008). 


\section{Limitations, Recommendations and Implications}

Several limitations can be mentioned in this study. The present parents sample was relatively small. Within further studies, it is recommended to examine a larger sample, to obtain more accurate diagnostic of the child disabilities. Further studies may compare the different perspective of the children and their parents, and between mothers and fathers. Such comparison may have an important contribution for better understanding the parents' knowledge and the child cyber world. As many parents are unaware of the potential harm that may be involved in usage of online social networks, it is important to promote specific workshops for parents, to introduce the cyberbullying phenomenon among adults and parents and for preventing any type of bullying and cyberbullying.Parents' awareness and identification of cyberbullying situations is central in an attempt to prevent it. Parents should be encouraged to take an active role in workshops in order to be able to identify their child cyberbullying involvement, as victim, a perpetrator or as a cyberwitness. Parental awareness and knowledge regarding the various activities of their child can prevent from the child engaging behavior problems or other risky behavior (Lippold, Greenberg, \& Collins, 2013). Conducting specific workshops for parents may promote their awareness of bulling and cyberbullying. Within such workshops, efficient and effective coping skills should be developed for parents to deal with their children, and specifically, with students with LD.

In addition, practical supportive involvement in should be offer to the parents, to encourage them to assist the child in coping with bullying/cyberbullying, how to effectively defend the child, to teach the child useful strategies against bullying, and to encourage the youth to share information with an adult and their parents (Vieno, Nation, Pastore, \& Santinello, 2009). The findings also raise the need for addressing parents and educational teams to the social aspect when designing, development and implementation of the anti-bullying intervention to confront bullying children online. It seems that such programs must include contents regarding support (from parents, family, adults, and peers), emphasizing the development of social skills, coping with loneliness and exclusion, and depressive mood of the adolescents with LD. In addition, special attention should be given to detecting children and adolescents with LD as victims and/or perpetrators of bullying or cyberbullying, and to formulate effective ways for coping with.

Table 1 Parent Perceptions of Their Child Being a Victim or a Perpetrator $(\mathrm{n}=85)$

\begin{tabular}{|l|l|l|l|l|}
\hline Variables & \multicolumn{2}{l|}{ Cybervictim } & \multicolumn{2}{l|}{ Traditional victim } \\
\hline Victimization & $n$ & $\%$ & $n$ & $\%$ \\
\hline Never occurred & 72 & 84.7 & 31 & 42.3 \\
\hline Verbal bullying & 3 & 3.5 & 40 & 47.1 \\
\hline Emails, SMS - received negative messages & 3 & 3.5 & -- & -- \\
\hline Physical bullying & -- & -- & 20 & 23.5 \\
\hline Property damage & -- & -- & 8 & 9.4 \\
\hline Victimization occurred during the last 6 months & 2 & 2.35 & 12 & 14.1 \\
\hline Victimization occurred during the last 12 months & 5 & 5.8 & 39 & 45.9 \\
\hline Never told anyone about being a victim & 3 & 3.5 & 2 & 2.4 \\
\hline Told somebody about being a victim & 5 & 5.9 & 45 & 52.9 \\
\hline & & & & \\
\hline Perpetrator & Cyber perpetrator & Traditional perpetrator \\
\hline Never occurred & 77 & 90.6 & 62 & 72.9 \\
\hline Verbal bullying & 0 & 0 & 12 & 14.1 \\
\hline Physical bullying & -- & -- & 9 & 10.6 \\
\hline Social exclusion & 0 & 0 & 8 & 9.4 \\
\hline Emails, SMS - sent negative messages & 4 & 4.8 & -- & -- \\
\hline
\end{tabular}

Table 2 Parents' Advice for Coping with Cyberbullying and Traditional Bullying

\begin{tabular}{|l|l|l|}
\hline Coping with cyberbullying & $n$ & $\%$ \\
\hline Blocking the messages & 53 & 62.4 \\
\hline Reporting to the police or other authorities & 60 & 70.6 \\
\hline Keeping a record of offensive emails or texts & 43 & 50.6 \\
\hline Telling somebody, consulting & 36 & 42.4 \\
\hline Changing email address or phone number, or password & 36 & 42.4 \\
\hline Asking the bullies to stop & 17 & 20 \\
\hline Ignoring the messages & 17 & 20 \\
\hline Fighting back & 2 & 2.4 \\
\hline
\end{tabular}




\begin{tabular}{|l|l|l|}
\hline Coping with traditional bullying & $n$ & $\%$ \\
\hline Tell an adult (as parent, teacher, school counselor, school principal) & 38 & 44.7 \\
\hline The child tried to help the victim & 25 & 29.4 \\
\hline Not to get involved then he/she saw bullying incidence & 13 & 15.3 \\
\hline Did not know how their child will deal with traditional bullying & 8 & 9.4 \\
\hline Did not answer & 1 & 1.1 \\
\hline
\end{tabular}

Table 3 Relationships Between Parents' Reports on Cyber and Traditional Bullying and Social- Emotional Measures

\begin{tabular}{|l|l|l|l|l|}
\hline Measures & $\begin{array}{l}\text { Cyber- } \\
\text { victims }\end{array}$ & $\begin{array}{l}\text { Traditional } \\
\text { Victims }\end{array}$ & $\begin{array}{l}\text { Cyber- } \\
\text { perpetrators }\end{array}$ & $\begin{array}{l}\text { Traditional } \\
\text { Perpetrators }\end{array}$ \\
\hline General social support & -.20 & $-.30^{*}$ & -.26 & $-.39^{* *}$ \\
\hline Family support & -.25 & -.18 & $-.32^{*}$ & $-.30^{*}$ \\
\hline Friends' support & -.08 & $-.35^{*}$ & -.17 & $-.45^{* *}$ \\
\hline Others' support & -.20 & -.18 & -.16 & -.27 \\
\hline General Loneliness & -.1 & $.42^{* *}$ & .20 & .17 \\
\hline Social Loneliness & -.13 & $.36^{*}$ & .14 & .16 \\
\hline Emotional Loneliness & .01 & $.42^{* *}$ & .22 & .16 \\
\hline Depressive mood & $.30 *$ & $.47^{* *}$ & $.31^{*}$ & $.29^{*}$ \\
\hline Traditional Victims & .16 & -- & .14 & $.47^{* *}$ \\
\hline Traditional Perpetrators & .23 & -- & $.48^{* *}$ & -- \\
\hline
\end{tabular}

Note: $* * p<0.01 * p<0.05$.

\section{REFERENCES}

[1] Asher, S.R., Hymel, S., \& Renshaw, P. D. (1984). Loneliness in children. Child Development, 55 (4), 1456-1464.

[2] Brighi, A., Melotti, G., Guarini, A., Genta, M.L., Ortega, R., Mora-Merchan, J., Smith, P.K., \& Thompson, F. (2012). Self-esteem and loneliness in relation to cyberbullying in three European countries. In: Q. Li., D. Cross, \& P. K. Smith (Eds.), Cyberbullying in the global playground: Research from international perspectives (pp. 32-56). Chichester: Wiley-Blackwell.

[3] USA Statistical Data (2014). Bullying in school and cyberbullying statistics. Retrieved from http://www.bullyingstatistics.org/content/school-bullying-statistics.html/ and http://nobullying.com/cyberbullying-statistics-2014/

[4] Campbell, M., Spears, B., Slee, P., Butler, D., \& Kift, S. (2012). Victims' perceptions of traditional and cyberbullying, and the psychosocial correlates of their victimization. Emotional \& Behavioral Difficulties, 17(3/4), 389-401.

[5] Dehue, F., Bolman, C., \& Vollink, T. (2008). Cyberbullying: Youngsters' experiences and parental perception. Cyberpsychology \& Behavior, 11(2), 217-223.

[6] Diagnostic and Statistical Manual of Mental Disorders (DSM-5). (2013). The American Psychiatric Association (APA). Retrieved from: http://www.psychiatry.org/psychiatrists/practice/dsm/dsm-5

[7] Dyson, L. (2003). Children with learning disabilities within the family context: A comparison with siblings in global self-concept, academic self-perception, and social competence. Learning Disabilities Research \& Practice, 18 (1), 1-9.

[8] Hartley, M. T., Bauman1, S., Nixon, C. L., \& Davis, S. (2015). Comparative study of bullying victimization among students in general and special education. Exceptional Children, 81(2) 176-193. DOI: $10.1177 / 0014402914551741$

[9] Heiman, T. Olenik-Shemesh, D., \& Eden, S. (2014). Cyberbullying involvement among students with ADHD: relation to loneliness, self-efficacy and social support. European Journal of Special Needs Education, doi: 10.1080/08856257.2014.943562

[10] Heiman, T., \& Olenik-Shemesh, D. (2013). Cyberbullying experience among adolescents with LD attending general and special education classes. Journal of Learning Disabilities. DOI: $10.1177 / 0022219413492855$

[11] Hen, M., \& Goroshit, M. (2014). Academic procrastination, emotional intelligence, academic self-efficacy, and GPA: A comparison between students with and without learning disabilities. Journal of Learning Disabilities, 47(2). 116-124. DOI: 10.1177/0022219412439325 
[12] Hershkowitz, I., Lamb, M. E., \& Horowitz, D. (2007). Victimization of children with disabilities. American Journal of Orthopsychiatry, 77 (4), 629-635. doi.org/10.1037/0002-9432.77.4.629

[13] Hinduja, S., \& Patchin, J. (2013). Social influences on cyberbullying behaviors among middle and high school students. Journal of Youth \& Adolescence, 42 (5), 711-722.

[14] Hinduja, S., \& Patchin, J. W. (2010). Bullying, cyberbullying, and suicide. Archives of Suicide Research, 14(3), 206-221. doi:10.1080/13811118.2010.494133

[15] Israeli Ministry of Education (2014). Learning disabilities- Definition. Retrieved from http://cms.education.gov.il/EducationCMS/Units/Shefi/LikuyeyLemida/yeda/Hagdara.htm (in Hebrew).

[16] Junoven, J., \& Gross, E. (2008). Extending the school grounds? Bullying experiences in cyberspace. Journal of School Health, 78(9), 496-505.

[17] Kokkinos, C.M., \& Antoniadou, N. (2013). Bullying and victimization experiences in elementary school students nominated by their teachers for specific learning disabilities. School Psychology International, 34 (6), 674-690.

[18] Kovacs, M., \& Beck, A. T. (1977). An empirical clinical approach toward a definition of childhood depression. In: J. Schlterbrant, J., \& A. Raskin (Eds.), Depression in childhood: Diagnosis, treatment and conceptual models (pp. 1-25). New York: Raven-Press.

[19] Law, D. M., Shapka, J. D., \& Olson, B. F. (2010). To control or not to control? Parenting behaviours and adolescent online aggression. Computers in Human Behavior, 26 (6), 1651-1656. doi:10.1016/j.chb.2010.06.013

[20] Li, Q. (2006). Cyberbullying in schools: A research of gender differences. School Psychology International, 27(2), $157-170$.

[21] Lippold, M. A., Greenberg, M. T., Graham, J. W., \& Feinberg, M. E. (2013). Unpacking the effect of parental monitoring on early adolescent problem behavior mediation by parental knowledge and moderation by parent-youth warmth. Journal of Family Issues. doi: 10.1177/0192513X13484120

[22] Livingstone, S., \& Helsper, E. (2008). Parental mediation and children's Internet use. Journal of Broadcasting \& Electronic Media, 52 (4), 581-599. doi: 10.1080/08838150802437396

[23] Madden, M., Cortesi, S., Gasser, U., Lenhart, A., \& Duggan, M. (2012). Parents, teens, and online privacy. PEW Research Center. Retrieved from http://www.pewinternet.org/2012/11/20/parents-teens-and-onlineprivacy/

[24] Mammarella, I. C., Ghisi, M., Bomba, M., Bottesi, G., Caviola, S., Broggi, F., \& Nacinovich, R. (2014). Anxiety and depression in children with nonverbal learning disabilities, reading disabilities, or typical development. Journal of Learning Disabilities, doi:10.1177/022219414529336

[25] Margalit, M., \& Al-Yagon, M. (2002). The loneliness experience of children with learning disabilities. In B.Y.L. Wong \& M. Donahue (Eds., The social dimensions of learning disabilities (pp.53-75). Hilisdale, N.J: Lawrence Erlbaum.

[26] Mason, K.L. (2008). Cyberbullying: A preliminary assessment for school personnel. Psychology in The Schools, 45 (5), 323-348.

[27] Mesch, G. (2009). Parental mediation, online activities, and cyberbullying. Cyberpsychology and Behavior, 12 (4), 387-393. doi: 10.1089/cpb.2009.0068

[28] Mishna, F. (2003). Learning disabilities and bullying: Double jeopardy. Journal of Learning Disabilities, $36(4), 336-347$.

[29] Mishna, F., MacFadden, R., Gadalla, T., Daciuk, J., Solomon, S., \& Cool, C. (2008). Cyberbullying Survey. Toronto, Ontario, Canada: University of Toronto.

[30] National Joint Committee on Learning Disabilities (NJCLD, 1994). Collective perspectives on issues affecting learning disabilities: Position paper and statement. Austin, TX: Pro-Ed.

[31] Olenik-Shemesh, D., Heiman, T., \& Eden, S. (2012). Cyberbullying victimization in adolescence: Relationships with loneliness and depressive mood. Emotional and Behavioral Difficulties, 17 (3/4), 361374.

[32] Olweus. D. (1993). Bullying in school: What we know and what we do. Psychology in the Schools, 40, 699-711.

[33] Ramsey, J. L., DiLalla, L. F., \& McCrary, M. K. (2015). Cybervictimization and depressive symptoms in sexual minority college students. Journal of School Violence. doi: 10.1080/15388220.2015.1100116

[34] Raskind, M.H., Margalit, M. \& Higgins, E.L. (2006). "My LD": Children's voices on the Internet. Learning Disability Quarterly, 29, 253-268.

[35] Rigby, K. (2013). Bullying in schools and its relation to parenting and family life. Family Matters, 92, 61 67.

[36] Rose, C., Monda-Amaya, L. E., \& Espelage, D. L. (2011). Bullying perpetration and victimization in special education: A review of the literature. Remedial and Special Education, 32, 114-130. 
[37] Ševčíková, A., Šmahel, D., \& Otavová, M. (2012). The perception of cyberbullying in adolescent victims. Emotional \& Behavioral Difficulties, 17(3-4), 319-328.

[38] Singer, E. (2005). The strategies adopted by Dutch children with dyslexia to maintain their self-esteem when teased at school. Journal of Learning Disabilities, 38 (5), 411-423.

[39] Smith, P.K., Mahdavi, J., Carvalho, M., Fisher, S., Russeel, S., \& Tippett, N. (2008). Cyberbullying: its nature and impact in secondary school pupils. Journal of Child Psychology and Psychiatry, 49(4), 376-385.

[40] Stadler, C., Feifel, J., Rohrmann, S., Vermeiren, R., \& Poustka, F. (2010). Peer-victimization and mental health problems in adolescents: Are parental and school support protective? Child Psychiatry \& Human Development, 41(4), 371-386. DOI: 10.1007/s10578-010-0174-5.

[41] Vieno, A., Nation, M., Pastore, M., \& Santinello, M. (2009). Parenting and antisocial behavior: A model of the relationship between adolescent self-disclosure, parental closeness, parental control, and adolescent antisocial behavior. Developmental Psychology, 45(6), 1509-1519. DOI:10.1037/a0016929.

[42] Vollink, T., Dehue, F., Mc Guckin, C., \& Jacobs, N. C. L. (2016). An introduction in cyberbullying research. In T. Vollink, F. Dehue, \& C. Mc Guckin (Eds.) Cyberbullying from theory to intervention (pp. 3-15). London, UK: Routledge.

[43] Zimet, G.D., Dahlem, M.W., Zimet, S.G., \& Parley, G.K. (1988). The multidimensional scale for perceived social support. Journal of Personality Assessment, 52, 30-41. 